Revista de la red interuniversitaria de estudios sobre las literaturas rioplatenses contemporáneas en Francia

$10 \mid 2014$

El XIX en el XX

\title{
La lección de los menores
}

\section{Claudia Rosa}

\section{OpenEdition}

Journals

\section{Edición electrónica}

URL: http://journals.openedition.org/lirico/1582

DOI: $10.4000 /$ lirico. 1582

ISSN: 2262-8339

Editor

Réseau interuniversitaire d'étude des littératures contemporaines du Río de la Plata

\section{Referencia electrónica}

Claudia Rosa, «La lección de los menores », Cuadernos LIRICO [En línea], 10 | 2014, Publicado el 15 marzo 2014, consultado el 22 septiembre 2020. URL : http://journals.openedition.org/lirico/1582 ; DOI : https://doi.org/10.4000/lirico.1582

Este documento fue generado automáticamente el 22 septiembre 2020

\section{c.) (i) (9)}

Cuadernos LIRICO está distribuido bajo una Licencia Creative Commons Atribución-NoComercialSinDerivar 4.0 Internacional. 


\title{
La lección de los menores
}

\author{
Claudia Rosa
}

\section{REFERENCIA}

Daniel Elías, Obra Poética, Colección El País del Sauce, Introducción, cronología, bibliografía y notas : Miguel Ángel Federik, Eduner- UNL, Santa Fe, 2012, 273 p.

1 Las dotes líricas de Daniel Elías vienen acuñadas en los textos de quienes lo nombran como un precursor: Carlos Mastronardi o Juan L. Ortiz lo citan como uno de sus maestros. Sobre esta senda, el poeta Miguel Ángel Federik coordina el segundo tomo de la colección "El país del Sauce" -que compila las ediciones críticas de dos libros : Las alegrías del Sol (1929) y Los arrobos de la tarde (1938), ambos póstumos-, y a través de la introducción, una cronología minuciosa y notas de prosapia genética, va sosteniendo la convicción de que el signo de la literatura entrerriana es la musicalidad simbolista. Ese signo constituye casi un hito, tanto formal como político, de un tipo y un grupo de poetas argentinos que desde los tiempos en que Entre Ríos se organiza como tal -un país dentro de un país- hasta nuestros días, erige una poesía que se basa principalmente en un mito plasmado en la musicalidad y la luz del campo.

2 La lectura que realiza Federik instala a Daniel Elías en un lugar ineludible para poder comprender las poéticas que inauguran Mastronardi y Juan L. Ortiz. En ese lugar se encontraría el origen del linaje de la contención de efusividades y de audacias formales, así como de un ostinato rigore que Elías practicaba con oficio. Este poeta de estirpe entrerriana (nacido en 1885 y suicidado, como antesala del signo lugoniano, en 1928) entendía que las formas mitológicas nacen en el campo, y que el gaucho incontaminado, o suficientemente alejado en el tiempo, era materia natural para una lírica que pedía a gritos abrirse camino. Tempranamente, logra ofrecer una salida al modernismo rubendariano : el poeta instala una nueva sonoridad cercana a la lengua de su geografía, la selva de Montiel. Con los materiales propios de una lengua criolla, sujetando la lírica heroica de su tiempo, evitando la narrativa de lo quejumbroso, se 
sitúa de pleno en ese concepto de Eliot de la poesía menor, que tanto dolor de cabeza ha dado a la crítica.

3 Se suele afirmar que un poeta es aquel que impone el silencio entre tantas sonoridades ruidosas. 0 que el silencio es una de las pruebas más difíciles que debe pasar el arte. En ese sentido sabemos que un poeta es la cara opuesta de un maestro, porque no se trata de enseñar ni de señalar sino de crear un espacio lírico en donde las palabras vayan adquiriendo un sentido propio, y en donde se tome plena conciencia de los ritmos de la lengua.

Eliot enseñó que se llama poesía menor a diferentes cosas en diferentes épocas, sin que haya ninguna connotación despreciativa en el uso del término. La fuerza de la poesía menor consistiría en actuar como una antena provisoria, catalizadora de tonalidades antiguas y memoriosas. Su valor especial radica en que constituye una poesía que tiene el oído atento a aquellas voces regionales, epocales, que necesariamente deben ser llevadas a la lengua culta. Son esos poetas quienes han comprendido, casi religiosamente, que no hay ventaja en ser publicado -Daniel Elías fue un poeta inédito - sino que lo valioso, lo que va a alimentar su trabajo, consiste en hacer circular los textos con carácter de precarios, de forma irregular, en el interior de un circuito de "compañeros de lengua" que van a atribuir el valor poético a esa experiencia de encontrar una nueva musicalidad en la nominación incipiente de lo que nos rodea. Es así como esta poesía adquiere un valor como experiencia poética para sus futuros lectores; el poeta se va haciendo lugar entre otros poetas y se va constituyendo en el prototexto literario de otros textos que podrán, gracias a su trabajo, encontrar una lengua literaria madura, con ciertas simpatías regionales, en donde sementar su escritura.

$5 \quad$ Es usual que estos poetas que anteceden a los grandes autores, aquellos que van a tener un lugar central en el sistema literario, pasen desapercibidos, sean publicados post mortem o que su obra merezca la atención crítica, como en este caso, casi 90 años después de haberse escrito. Es que los prototextos que construyen la sólida base de una poética, aquellos que ponen las primeras reglas o principios de una lírica sobre la cual se va a edificar la lírica mayor, suelen tender a disolverse sin recibir la atención del lector. Y van lentamente convirtiéndose en autores de culto, en aquellos poetas ineludibles que todo poeta debe leer. Este es el caso de Daniel Elías, y su valor radica en que es posible estudiar en él los cambios temáticos y estilísticos para poder comprender las ulteriores escaladas de poetas como Carlos Mastronardi, Juan L. Ortiz o Arnaldo Calveyra. Son textos promisorios, de ejecución muy estable y madura, que modelizan claramente el lenguaje literario entrerriano en una tarea arqueológica de la lengua y de sus sonoridades. He allí el "depurado lirismo" de este poeta, que lleva a cabo una verdadera superación del modernismo y cuya naturaleza poética llega a un estadio tal de sazón y madurez que lo vuelve imprescindible a la hora de entender los clivajes que el simbolismo francés produjo en la literatura argentina.

El modernismo fue una de las más sostenidas tradiciones de nuestra poesía ; dominarlo implicó convertirlo en una vocación clásica, sujetar lo inmediato, lo que todavía no es mito y concederle mesura. Y sobre todo establecer una política de la lengua que pueda darse la mano con una política de la escritura nacional. Y para articular la lengua y la escritura fue necesaria la precisión y la calma; esas han sido las lecciones de Daniel Elías, que adoptó un método riguroso para construir una sonoridad y escribir como si se tratase de un tiempo recobrado. La gran lección del poeta menor fue la lucidez del 
pudor, dominar la emoción y que el oficio tiene su regla y solo allí se encuentra su nobleza.

Daniel Elías pertenece a una tradición entrerriana muy cercana con lo oriental, especialmente con las poéticas (heredadas de Herrera y Reissig) que reivindicaban un paisaje, una flora, una fauna y un tipo especial de "criollicidad" diferentes de los de la provincia de Buenos Aires. Mastronardi en Memorias de un provinciano afirma: "Daniel Elías, cuyos sonetos visuales y precisos jamás desmienten su noble ascendencia

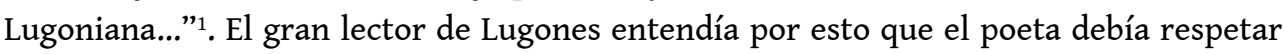
el lenguaje de tal modo que todo término inevitablemente genérico debía ser deplorado. Esta herencia del poeta civil debía ser capaz de presentarnos cosas únicas, impares, y no detenerse en octosílabos pintorescos. De hecho, la crítica contemporánea a Daniel Elías lo había leído en clave dariana, con un cierto idealismo propio de su posición de clase. Es Miguel Ángel Federik quien por primera vez relee a Daniel Elías bajo la otra herencia lugoniana : la de entender la poesía como medio de conocimiento, y el idealismo como una reacción a los vitalismos y materialismos propios de lo que podríamos llamar "tendencias de la actualidad" del movimiento poético. El carácter delicuescente de los poemas de Elías va más allá del simbolismo elegíaco, y fue él quien enseñó que la exquisitez del vocabulario pone el poema al recaudo del intimismo, mientras que todo parece fluir de una inspiración adámica. Sin embargo, es Federik quien marca que tanto el modernismo lugoniano como el herreriano tienen cepas provenzales, y son esas cepas las que le dan un tono provincial típico. Será esa tonalidad la que las próximas generaciones de poetas seguirán haciendo sonar. Más allá de los trabajos de la agricultura y la ganadería, los días de la campaña y sus alegrías, el ocio del amor campesino y las holgazanerías de la caza y de la pesca, la poesía de Daniel Elías mantiene el rusticismo de las zonas ribereñas y rurales, y maneja con precisión las imágenes soleadas de su paisaje, en donde nunca se hace presente la ciudad, porque no se trata de una tradición comarcana o poco cosmopolita, sino justamente de construir una zona poética nueva.

8 Luis Alberto Ruiz postula la existencia de una escuela poética entrerriana que poseería un estilo distinguible y cuya característica central sería "el sentimiento de comunión con la tierra, en la virtual impregnación del alma entrerriana por su paisaje”, aclarando que el paisaje está entendido en su proyección "metafísica, cósmica, panteística, ontológica". Y dentro de esta mitificación geológica incluye la obra de Gerchunoff, el poema "Luz de provincia" de Mastronardi, y Las alegrías del sol de Daniel Elías :

En una obra que dedicamos a Entre Ríos postulamos una "escuela poética entrerriana" para señalar la real existencia de un estilo distinguible, de un modo personal entrerriano, identificable con la calidez emocional de sus mejores poetas, en el sentimiento de comunión con la tierra, en la virtual impregnación del alma entrerriana por su paisaje. Paisaje no en el sentido plásticamente material, estético, sino en su proyección metafísica, cósmica, panteística, ontológica; en su sagrado carácter de mito geológico. Esta mitificación del hombre rural y del paisaje provinciano es claramente perceptible en obras como Calandria, de Leguizamón, Montielero, de Balboa Santamaría, en Los Gauchos judíos de Gerchunoff, o en Palo a Pique, de Villagra, en Las alegrías del Sol, de Daniel Elías, en el poema "Luz de provincia" de Mastronardi, en el parcialmente inédito El país de Los Dorados, de Eduardo Brizuela Aybar, en casi toda la poesía de Juan L. Ortiz, de Carlos Alberto Álvarez, Jorge Enrique Martí, Marcelino M. Román, José María Díaz. Hasta la poesía ciudadana rescató los antiguos o los cambiantes perfiles de las casas y las calles, de los extramuros o de los arrabales, como en los Motivos de Paraná, de Murga, en los recuerdos paranaenses de Luís Sadí Grosso, en las elegíacas visiones de San Miguel, 
elaboradas fastuosamente por Sola González, en las "urbanidades" de Amaro Villanueva, en las reconstrucciones novelescas de María Esther de Miguel, de Juan José Manauta, de Juan Pedro Cartosio. ${ }^{2}$

9 Así inscripta la genealogía de este libro, que deviene nuevo, la riqueza de esta poesía surge de diferentes fuentes, tanto de la historia del sistema literario como de su lengua poética. Esta obra fue cuidada no solo en sus acentos y sus ritmos, sino que fueron restituidos a estos textos el mundo en donde emergieron en una lúcida y esclarecedora introducción, un trabajo de una riqueza poco usual ya que muy pocas veces los poetas se avienen a leer con generosidad y a dejar publicada la lectura que hacen de sus maestros. La colección El País del Sauce está dirigida por Sergio Delgado, quien una vez más logra el cometido de ir edificando un sistema de textos que construyen una zona literaria.

\section{NOTAS}

1. Mastronardi, Carlos, Memorias de un provinciano, Buenos Aires : Ed. Culturales Argentinas, 1967, p. 105.

2. Ruiz, Luis Alberto, “Consideraciones sobre la literatura provincial”, en Historia de la literatura entrerriana (mimeo), 1990, p. 24.

\section{AUTORES}

\section{CLAUDIA ROSA}

Universidad Nacional de Entre Ríos. Universidad Nacional del Nordeste 